Ensino, Saúde e Ambiente - V4 (3), pp. 82-92, dez. 2011

\title{
A FORMAÇÃO DE PROFESSORES DE CIÊNCIAS: MEMÓRIAS DOS ATORES DO INSTITUTO DE EDUCAÇÃO DO RIO DE
}

\section{JANEIRO}

A TEACHER OF SCIENCE: MEMORIES OF ACTORS

INSTITUTE OF EDUCATION RIO DE JANEIRO

Luiza Oliveira, Ana Maria Leal Almeida, Marinea Rodrigues, Hermes Ferreira e Patrick Damasceno

Universidade Severino Sombra- Campus Maricá

Curso de Pedagogia e Núcleo de Pesquisa e Extensão - NAPE/MARICÁ

\section{RESUMO}

Este artigo apresenta uma discussão acerca da Formação de Professores de Ciências no Brasil, a partir da análise dos fatos históricos que constituíram uma escola de Formação de Professores. Esta análise foi feita por meio da análise de fotografias produzidas pelos atores escolares. Este texto é recorte de uma pesquisa mais ampla que investiga a Formação de Professores a partir da análise das Histórias de Vida de Professores e da Memória do Patrimônio das Escolas. Neste artigo foram analisadas as memórias do Instituto Superior de Educação do Estado do Rio de Janeiro a partir de um estudo iconográfico, com dados oriundos de projetos de Pesquisa fomentados pela FAPERJ e pela FUNADESP. Para tanto, alguns momentos foram privilegiados: décadas de 1930 a 1950. Essas são décadas emblemáticas, pois revelam os anos do início do processo de industrialização do Brasil, sendo, portanto, o momento da modernização do país. Além disso, os anos 30 marcam a inauguração do prédio atual do Instituto Superior de Educação do Rio de Janeiro (ISERJ), acontecida em 1930, quando a escola era denominada de Escola Normal. Foi possível perceber as relações subjetivas produzidas pela Escola Moderna e como esse tipo de produção instituiu o lugar do Professor de Ciências.

Palavras-chave: Formação de Professores, Ensino de Ciências, Memória, Fotografia.

\section{ABSTRACT}

This article presents a discussion of Teacher Education Sciences in Brazil, from the analysis of historical facts that constituted a school of Teacher Training. This analysis was done by analysis of photographs produced by the school actors. This text is part of a research that investigates the broader Teacher Training from the analysis of the Life Stories of Teachers and Memory Heritage Schools. In this article we analyzed the memories of the Institute of Education of the State of Rio de Janeiro from an iconographic study, with data from research projects promoted by FAPERJ and the FUNADESP. Therefore, some moments were privileged: decades from 1930 to 1950. These decades are emblematic, because they reveal the years of the beginning of the industrialization of Brazil, therefore, the time of modernization. In addition, the 30year mark the inauguration of the current building of the Institute of Education of Rio de Janeiro (ISERJ), took place in 1930, when the school was called the Normal 
School. It was possible to understand the subjective relations produced by the Modern School and how this type of production established the place of Professor of Sciences.

Keywords: Teacher Education, Science Education, Memory, Photography.

\section{INTRODUÇÃO}

A Formação de Professores é tema relevante, pois somente na década de 1990 tornou-se objeto de estudo na Educação. Este fato pode ser explicado pelos modelos de ensino que perpassaram a história da Educação e que negavam o lugar do professor na constituição do processo de aprendizagem. No Ensino de Ciências, podemos evidenciar os modelos do Movimento da Mudança Conceitual (MMC) e o modelo oriundo da teoria piagetiana. O primeiro apenas demonstrava a importância da ruptura com as concepções prévias da criança, mas não discutia a construção do conhecimento, já a teoria piagetiana, embora discutisse a construção do conhecimento, reconhecia a ação do professor apenas como facilitadora do processo de ensinoaprendizagem; ou seja, a ação do professor nesse modelo não é determinante para a construção do conhecimento pela criança.

A opção de discutir como esses modelos contribuíram para a constituição do lugar do professor de ciências a partir da recuperação da Memória dos atores escolares pode ser afirmada pelo fato de que esta técnica de pesquisa traz à cena os lugares institucionais nas vozes dos próprios sujeitos.

A forma de resgate da memória escolhida é o estudo iconográfico, que se dá por meio da análise de documentos que contêm imagens fixas, impressas, desenhadas ou fotografadas, como fotografias e gravuras.

Assim, apesar de seu potencial em captar os múltiplos planos da realidade visível, inclusive alguns mais "abstratos", cabe aqui fazer uma observação quanto à limitação da fotografia, pois enquanto a imagem sonora em movimento poderia mais facilmente auto-explicar-se e induzir uma interpretação, a fotografia isolada, por mais rica em aspectos visuais e simbólicos, dificilmente consegue propor uma explicação ou uma interpretação. A fotografia tende sempre a ficar no limite da constatação, no caso de uma questão ou característica socioetnográfica. Vai ser o "olhar" do pesquisador que vai identificar nela a problemática socioantropológica. Sem isso as fotografias parecem produzir apenas descrições rasas (...). Não se trata apenas de descrever (de forma rasa) o sistema social, político e religioso, mas captar os significados e os valores que ordenam e dão sentido a essas formações sociais. Para então inscrevêlos de uma forma legível; proceder esta descrição densa, para que se possa transmitir a outrem (sejam nossos pares ou a sociedade envolvente) as lógicas particulares dessa outra cultura, de forma que podemos tornar legível ou inteligível estes "saberes locais" resultantes da diversidade da experiência humana (GODOLPHIM, 1995, pp. 165-6) 
Assim o que pretendemos com esse relato inicial de uma pesquisa é discutir o de professores de ciências a partir da análise das relações entre Memória e formas de relação de produção, de saber e de poder características da sociedade moderna.

\section{ANÁliSE DAS FOTOGRAFIAS: MEMÓRIAS DO INSTITUTO DE EDUCAÇÃO}

As fotos apresentadas e analisadas abaixo compõem o acervo do Centro de Memória do Instituto Superior de Educação do Rio de Janeiro (ISERJ) e foram produzidas a partir dos olhares e dos discursos de seus atores.

As fotos representam as décadas de 1930 a 1950. Estas décadas são emblemáticas peara pensar o ensino de ciências no Brasil, pois revelam os anos do início e da afirmação do processo de industrialização do Brasil, sendo, portanto, o momento da modernização do país. Além disso, os anos de 1930 marcam a inauguração do prédio atual do Instituto Superior de Educação do Rio de Janeiro (ISERJ), acontecida em 1930, quando a escola ainda era denominada de Escola Normal.

Nos anos de 1930 vivemos o auge de uma série de revoluções e movimentos que tinham por objetivo promover rupturas sociais, políticas e econômicas com a velha ordem oligárquica. O ponto culminante dessas revoluções foi a Revolução de 1930. As críticas à velha ordem social originaram-se, no Brasil, como consequência da crise mundial de 1929. O país teve que se transformar em cenário industrializado, pois não tinha mais mercado consumidor para o que sua agricultura produzia, sobretudo, café, pois os países da Europa e os Estados Unidos estavam em crise. Esses foram anos do governo de Getúlio Vargas: 1930 a 1945.

Há associação direta entre essa nova ordem social e o desenvolvimento da escola pública e laica no Brasil. As novas formas de relação de produção instituídas pela industrialização geraram novas formas de relação de saber, pois a fim de a população tivesse condições mínimas de atender às demandas do novo mercado de trabalho, a escola não podia ser a religiosa, mas precisava ser laica a fim de divulgar o conhecimento produzido pela Ciência, a fim de formar o trabalhador para operar as máquinas; e, também, precisava ser oferecida a um maior número de segmentos da 
população. Assim, foram produzidas novas exigências educacionais que podem ser resumidas na demanda da educação moderna pela escola pública, universal e gratuita.

Na educação brasileira, a luta pela afirmação da ordem da sociedade moderna é representada pelo Movimento dos Pioneiros da Educação Nova, de 1932, que ao evidenciar a educação como um direito individual e universal, exige uma escola pública, gratuita, obrigatória e laica no Brasil. O Movimento dos Pioneiros da Educação Nova teve como seus principais líderes Fernando de Azevedo, Lourenço Filho e Anísio Teixeira. A Escola Normal, atual ISERJ, foi cenário do Movimento dos Pioneiros da Educação Nova. Vejamos a foto abaixo.

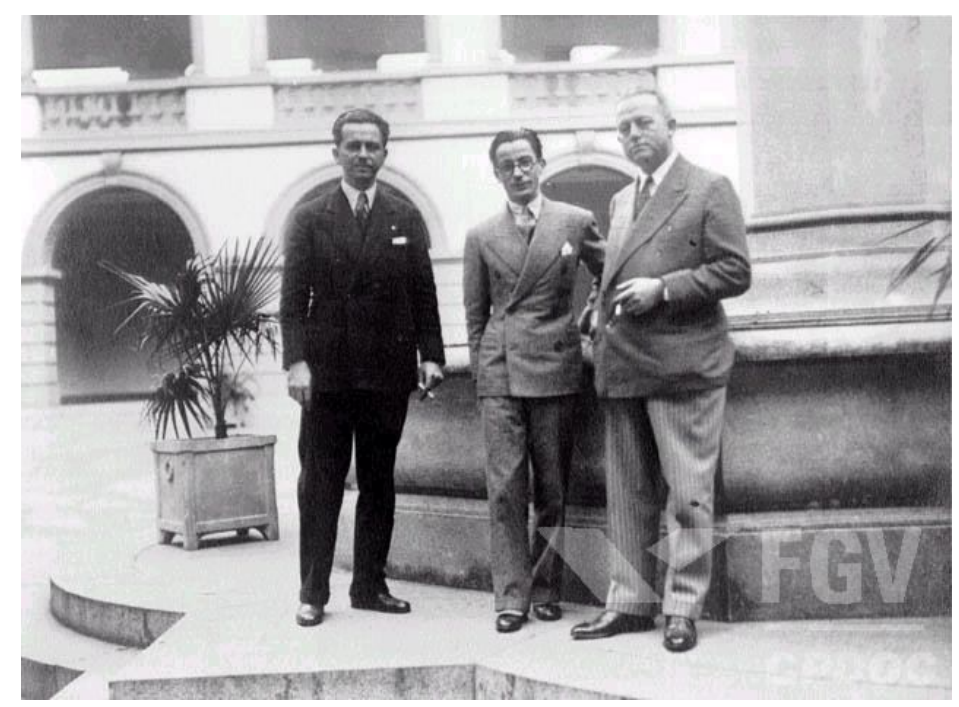

Lourenço Filho, Anísio Teixeira e Almeida Jr. no Instituto de Educação em 1932. Fonte: Centro de Memória do ISERJ/Arquivo Lourenço Filho. CPDOC / FGV.

Assim, a Escola Normal, atual Instituto Superior de Educação do Rio de Janeiro, é emblemática para entendermos os vínculos entre formas de relação de produção, de saber e de poder características da sociedade moderna com a educação brasileira e seus subtemas, formação de professores e modelos de aprendizagem.

Os novos espaços arquitetônicos das escolas eram símbolos da nova ordem, pois rompiam com a arquitetura das escolas religiosas.

(...) edifício escolar deve ainda contribuir para a educação estética por sua arquitetura e sua decoração. Não há meio mais eficaz para a educação do gosto popular do que por, sob os seus olhos, nos edifícios públicos, e, sobretudo, naqueles destinados à educação popular, exemplares perfeitos 
de arquitetura. (FERNANDO DE AZEVEDO, "A nova política de edificações escolares", Boletim de Educação Pública, n.1, 1930, p. 88)

Vejamos o que se dizia sobre a Escola Normal à época:

A escola technologica de mestres e contra-mestres, servida de laboratório de psycotechnica e orientação profissional, e a Escola Normal, remodelada em suas futuras installações, é que serão os grandes centros de preparação e disseminação da mestrança e do professorado incumbidos da realização integral dos novos ideaes. (FERNANDO DE AZEVEDO. "A Escola Nova e a Reforma". Boletim de Educação Pública, n. 1, 1930. p. 23).

Nessas reuniões, que constituíam um refrigério, uma pausa reconfortante, em meio àquela atividade febril, e às vezes, áspera, Fernando de Azevedo nos fazia apreciar as belas fotografias que iam sendo tiradas dos aspectos mais relevantes dos novos prédios escolares que estavam sendo construídos, em estilo tradicional brasileiro. Eram momentos de alegria em ver como ia sendo traduzida em pedra e cal toda uma nova filosofia de educação, em que se procurava dar às crianças e adolescentes um novo ambiente, em que a comodidade e a adequação às finalidades próprias se aliava a um alto sentido de beleza. (PASCHOAL LEMME. Memórias 2, São Paulo: Cortez e INEP, 1988, p. 41).

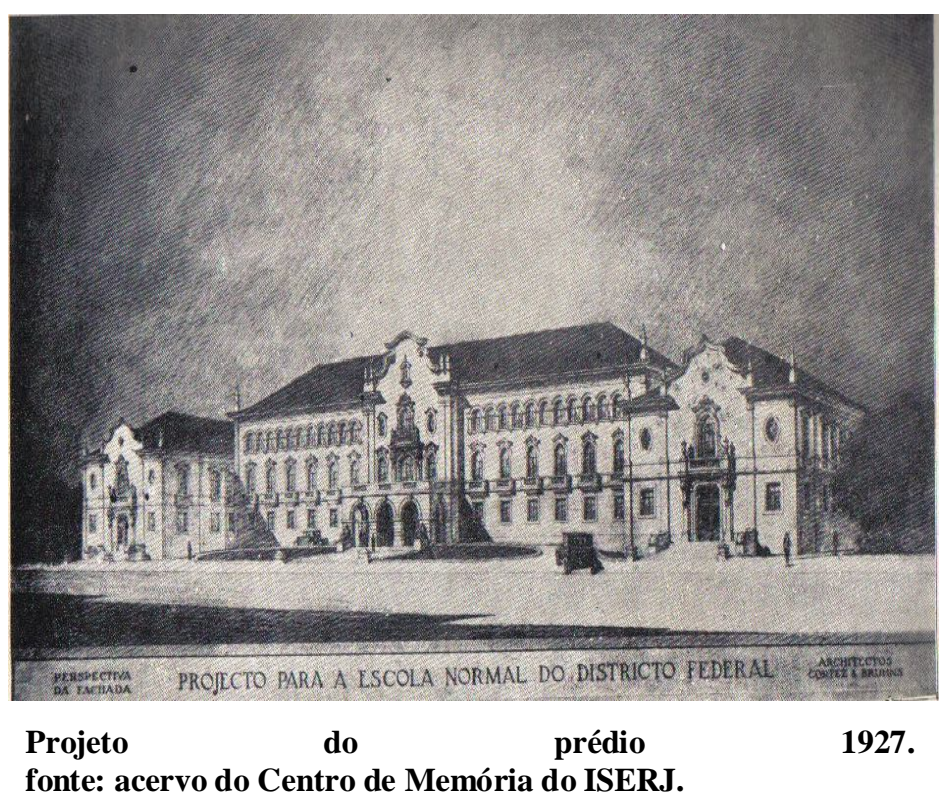

O espaço arquitetônico da Escola Normal revelava a seriação que se esperava da escola moderna em relação à formação das crianças. A perspectiva era da formação por etapas de desenvolvimento cognitivo. Os três andares do prédio da Escola Normal foram ocupados pelas escolas Primária, Secundária e de Professores e suas respectivas administrações. Um anexo foi construído para o funcionamento do Jardim de Infância, termo oriundo da ideia de que a criança precisava ser estimulada para desenvolver as suas potencialidades, ou seja, as operações cognitivas inerentes ao desenvolvimento cognitivo. 
A constituição arquitetônica revelava também aspectos do Movimento Higienista, típico movimento das primeiras décadas do século $\mathrm{XX}$, que revelava a preocupação com a saúde da criança com objetivos de saneamento, a fim de evitar problemas sociais futuros, inclusive, em relação a vícios, comportamento inadequados. Assim, existiam no prédio instalações no andar térreo para os serviços médico e dentário. Também andar térreo estava situado (e ainda está) o ginásio de esportes, que à época tinha a concepção de controle dos corpos e preparação para atividades esportivas de competição.

E, apesar dos ideais do Movimento dos Pioneiros da Educação Nova - a educação como um direito individual e universal, as escolas modernas atendem ao modo de produção capitalista, o objetivo, revelado, inclusive, pelo espaço arquitetônico, era conformar às pessoas à nova social. $\mathrm{O}$ prédio do Instituo de Educação foi instituído como modelo das relações subjetivas da escola moderna, modelo da estratégia predominante de poder da Modernidade - a disciplina.

A própria arquitetura facilita as coisas: "constroem-se paredes, distribuem-se espaços, organizam-se corredores, vazam-se portas, dividem-se compartimentos, espalham-se degraus, destacam-se púlpitos e "observatórios" de tal forma que o menor movimento pode ser registrado ou observado" (GUIRADO, 1996, p. 64)

As fotos abaixo expressam estas relações subjetivas da Escola Moderna.

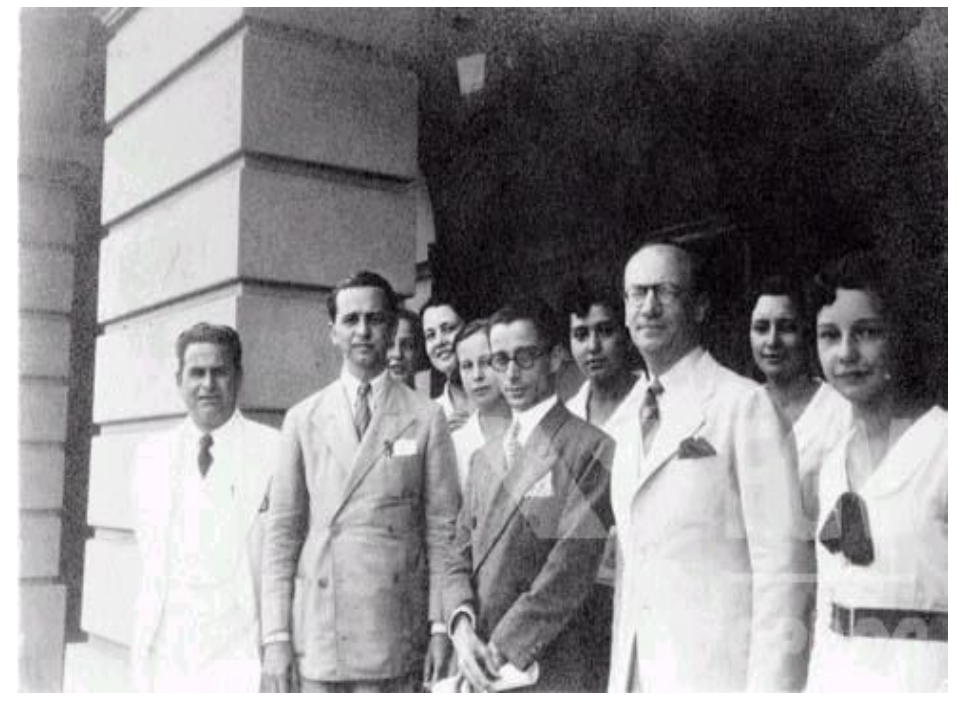


Lourenço filho, Anísio Teixeira, Mário Paulo de Brito e alunas do instituto de educação - década de 30.

Fonte: Centro de Memória do ISERJ/Arquivo Lourenço Filho CPDOC/FGV

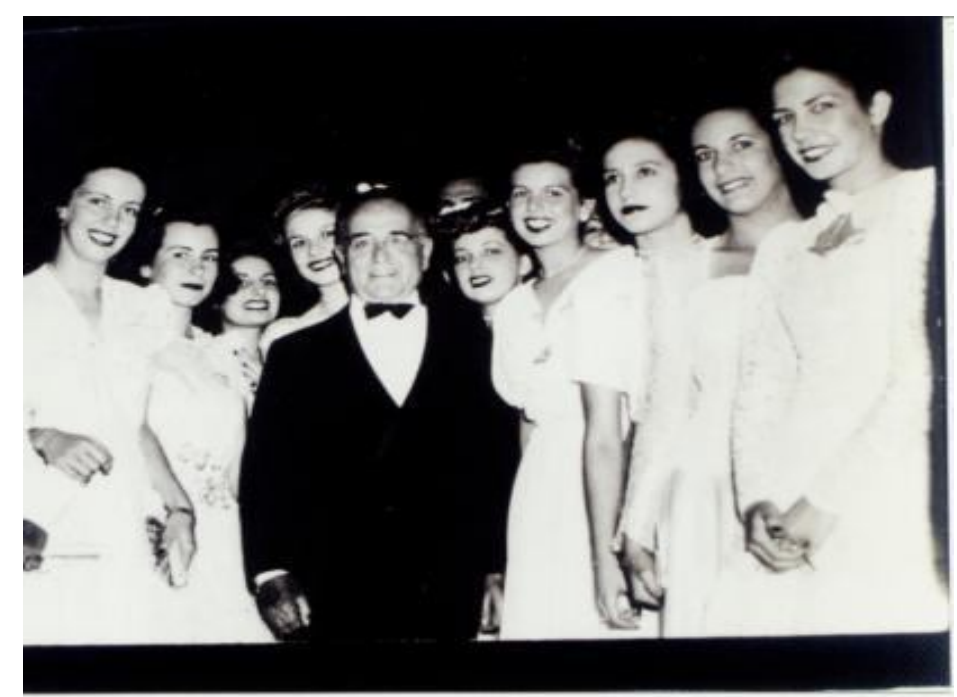

As normalistas - Vargas paraninfo em festa de formatura. Fonte: acervo do Centro de Memória do ISERJ

$\mathrm{Na}$ primeira os grandes nomes da Educação, professores do Instituto de Educação, Anísio Teixeira e Lourenço Filho, aparecem em primeiro plano que se sobrepõe na imagem às alunas. Remetendo à estrutura hierárquica que institui relações de subordinação e níveis sucessivos de poderes, de situação e de responsabilidades. Na segunda podemos ver o presidente Getúlio Vargas em dia de visita à Escola Normal. O Instituto de Educação era referência da educação moderna, assim a presença do Presidente da República era frequente.

\section{MEMÓRIAS E PRODUÇÃO DE SUBJETIVIDADE: MODELOS DE ENSINO EM CIÊNCIAS NA ORIGEM DA ESCOLA MODERNA}

A Área de Ensino de Ciências construiu modelos acerca do processo de construção de conhecimento científico nos quais é possível identificar a abordagem positivista, característica da escola moderna, que pudemos discutir acima a partir da análise das imagens do antigo Instituto de Educação, atual ISERJ. 
Um dos modelos é o da Mudança Conceitual de Posner, típico dos anos de 1950 e das décadas seguintes, que estabelece analogia entre a concepção kuhniana sobre o progresso da ciência e o processo de aquisição de conhecimento científico pelas pessoas. Ao propor a necessidade do estabelecimento da insatisfação com as concepções prévias existentes, este modelo propõe uma metodologia de ensino que gere insatisfação com as concepções dos alunos a fim de gerar desequilíbrio dessas concepções e afirmação da concepção científica (ARRUDA e VILLANI, 1994). As críticas indicam que esse é um modelo que não gera explicações de como se constroem os processos cognitivos. Portanto, não produz explicações acerca de como o aluno aprende e nem de qual seria a função do professor. Mas, nos remete à ideia de que o aluno é simples receptáculo dos conceitos científicos e que o professor deve apenas construir metodologias que desqualifiquem as concepções "erradas" dos alunos.

Outro modelo é o da Teoria do Desenvolvimento de Piaget, característico dos anos de 1950, mas com afirmação no Ensino de Ciências nas décadas de 1970 e 1980, qual analisa a construção da inteligência nos aspectos que favorecem a adaptação do homem à sociedade. Para Piaget (1986), a construção do conhecimento é um processo contínuo, caracterizado por diversos estágios, que definem um momento de desenvolvimento da inteligência ao longo do qual a criança constrói estruturas cognitivas. O caminho é de uma lógica rudimentar infantil à lógica formal, característica da Ciência. E há uma prevalência do sujeito cognitivo sobre o meio, pois é o modus operandi característico do sujeito que determina a aprendizagem. O professor é, então, um mero facilitar desse processo. Piaget minimiza a importância do contexto histórico social, da Cultura, da Linguagem.

A abordagem piagetiana é também característica das perspectivas da escola moderna, haja vista a explicação científica acerca do desenvolvimento cognitivo, a possibilidade de seriação do ensino justificada a partir das características de cada estágio do desenvolvimento.

Os dois modelos apresentados, de Posner e de Piaget, característicos do ensino e da pesquisa da origem da Área de Ensino de Ciências, nos remetem ao sujeito da Modernidade, sinônimo de indivíduo, afirmado por uma filosofia do sujeito que tem um caráter a-histórico, que produz uma concepção que dá prevalência ao sujeito sobre o objeto no ato de construção do conhecimento. 
Ensino, Saúde e Ambiente - V4 (3), pp. 82-92, dez. 2011

Um aspecto marcante da década de 1960 foi a chegada ao Brasil das teorias cognitivistas, que consideravam o conhecimento como sendo um produto da interação do homem com seu mundo e enfatizavam os processos mentais dos estudantes durante a aprendizagem. No entanto, somente no início dos anos 1980 é que essas teorias passaram a influenciar significativamente o ensino de ciências. As teorias de Bruner e o construtivismo interacionista de Piaget valorizavam a aprendizagem pela descoberta; o desenvolvimento de habilidades cognitivas; sugeriam que os estudantes deveriam lidar diretamente com materiais e realizar experiências para aprender de modo significativo e que o professor não deveria ser um transmissor de informações, mas orientador do ensino e da aprendizagem (NASCIMENTO E OUTROS, 2010, p. 228).

O professor de ciências era um facilitador, um orientador, como expresso na citação acima, mas não deveria interferir no processo de construção do conhecimento, pois era preciso respeitar os níveis de desenvolvimento cognitivo da criança que se realizavam por meio do desenvolvimento das operações cognitivas, em relação ao meio, mas sem a sua determinação a partir da Cultura, da Linguagem.

A Formação de professores, incluindo os professores de ciências, acompanhou os diversos modelos de aprendizagem, que acabaram por tirar de cena o professor diante de expectativas empiristas ou constutivistas-espontaneístas

No Brasil, com a Abertura Política em meados dos anos 80 e com a produção de um discurso crítico na Educação nos anos 90, a Área de Ensino de Ciências vem apresentando aproximações de uma abordagem histórico-social do processo de aprendizagem. O objetivo é romper com o sujeito a-histórico instituído na afirmação d área de Ensino de Ciências como campo de ensino e pesquisa.

Esta abordagem vem se constituindo a partir da perspectiva histórico-cultural de Vygotsky, que, embasada no discurso marxista, ressalta a importância da interação social no processo de construção do conhecimento. (VYGOTSKY, 2001).

Apresenta, assim, um sujeito que de fato é diferente do sujeito cartesiano, pois se constitui em ato, nas relações sociais, é um sujeito histórico, constituído a partir das condições de possibilidade político-econômico-sociais, e a partir do outro da Cultura e da Linguagem.

Esta ênfase epistemológica aproxima a área de Ensino de Ciências das concepções mais políticas e traz um novo lugar para o professor, pois a relação do homem com o mundo é mediada por instrumentos, ferramentas. São os instrumentos técnicos e os sistemas de signos que fazem a mediação dos homens entre si e deles com o mundo. A linguagem é um signo mediador, pois traz conceitos elaborados culturalmente. Vygotsky, assim, nos remete a dois níveis no desenvolvimento do 
sujeito psicológico - nível interpsicológico e nível intrapsicológico. Mas, o que pode parecer determinismo do Social, da Cultura, da Linguagem nos revela um jogo dialético, pois produz também sujeitos únicos, singulares. Com a internalização (microgênese) das práticas culturais, que constituem o desenvolvimento humano (sociogênese), Vygotsky descreve a passagem de ações realizadas no plano social para ações internalizadas como um processo e é isso que constitui o sujeito, em sujeito singular e social instituído no mesmo ato. A criança se desenvolve na medida em que, mediada por aquele que está por mais tempo na regra do jogo, se apropria pela cultura elaborada. Aprendizado e desenvolvimento são indissociáveis. Aliás, o aprendizado precede o desenvolvimento. Afirmação que traz à cena a importância do professor.

\section{CONSIDERAÇÕES FINAIS}

Este artigo discute os vínculos entre as condições de possibilidade da escola moderna e os modelos de aprendizagem em ciências. Para tanto, analisamos um recorte da Memória do ISERJ - antigo Instituto de Educação, a fim de entender tais condições na formação do professor de ciências.

Foi possível entender que é importante afirmar o lugar do professor, pois nos modelos contemporâneos de Educação - aqui representados pela teoria de Vygotsky, é possível entender que é a aprendizagem que produz o desenvolvimento cognitivo e não o inverso, como teorias da escola moderna afirmavam.

Isso nos permite pensar a importância do saber forma da escola e da intervenção do professor. No entanto, é necessário avaliar a escola, não no sentido da meritocracia, mas avaliar os aspectos de mediação desenvolvidos pela escola e que

foram negados pela escola moderna. É preciso, assim, formar o professor para ser mediador

\section{REFERÊNCIAS}

ARRUDA, S. e VILLANI, A. "M udança Conceitual no Ensino de Ciências". Cadernos Catarinenses de Ensino de Física, v. 11, n. 2, ago./1994, pp. 88-99.

AZEVEDO, F. "A nova política de edificações escolares", Boletim de Educação Pública, n.1, 1930.

GODOLPHIM, N. A Fotografia como Recurso Narrativo: Problemas sobre a Apropriação da Imagem enquanto Mensagem Antropológica Horizontes Antropológicos, Porto Alegre, ano 1, n. 2, p. 161-185, jul./set. 1995. 
GUIRADO, M. "Poder Indisciplina: os surpreendentes rumos da relação de Poder". JÚLIO GROPPA AUINO (ORG.). Indisciplina na Escola: alternativas teóricas e práticas. 13ª edição. São Paulo: Summus, 1996.

NASCIMENTO, F. E OUTROS. Ensino de Ciências no Brasil: História, Formação de Professores e desafios atuais. Revista HISTEDBR On-line, Campinas, n.39, p. 225249, set.2010.

LEMME, P. Memórias 2, São Paulo: Cortez e INEP, 1988

PIAGET, J. Seis Estudos em Psicologia. 13 ${ }^{\mathrm{a}}$ edição. Rio de Janeiro: ForenseUniversitária, 1986.

VYGOTSKY, L. Pensamento e Linguagem. 10ª edição. Petrópolis: Vozes, 2001. 